\title{
EVALUATION OF CYCLIC ADENOSINE MONOPHOSPHATE AND NEUROTRANSMITTERS IN EXPERIMENTAL OBESITY: IMPACT OF BLACK PEPPER AND COFFEE AQUEOUS EXTRACTS
}

\author{
SHADIA FATHY ${ }^{1}$, YASMIN ABDEL LATIF ${ }^{2 *}$, ZAKARIA EL-KHAYAT $^{2}$, MAHA MOUSTAFA ${ }^{1}$, ABDEL RAZIK FARRAG ${ }^{3}$, \\ AYA FARAHAT ${ }^{1}$
}

${ }^{1}$ Department of Biochemistry, Faculty of Science, Ain Shams University, Cairo, Egypt. ${ }^{2}$ Department of Medical Biochemistry, National Research Centre, Cairo, Egypt. ${ }^{3}$ Department of Pathology, National Research Centre, Cairo, Egypt. Email: jassy_83@hotmail.com

\author{
Received: 09 August 2016, Revised and Accepted: 29 August 2016
}

ABSTRACT

Objective: This study aims to evaluate the effect of black pepper and coffee extracts on chronic and acute experimental-induced obesity and energy homeostasis.

Methods: Rats were divided into 10 groups including control, high-fat diet (HFD), triton, HFD+triton, black pepper+HFD, black pepper+HFD+triton, coffee+HFD, coffee+HFD+triton, mixture+HFD, and mixture+HFD+triton groups. Blood glucose, serum insulin, and insulin resistance were estimated. Body mass index, food efficiency intake, and body weight gain were calculated. Lipid profile, liver and kidney functions were measured, serum and brain cyclic adenosine monophosphate (cAMP) was estimated, and brain neurotransmitters were measured by high-performance liquid chromatography. Furthermore, histopathology of liver was performed.

Results: Findings showed that blood glucose, insulin resistance, lipid profile, kidney and liver functions as well as brain cAMP and neurotransmitters were significantly increased, concomitant with a significant decrease in insulin resistance and serum cAMP in both HFD and triton-induced obesity groups compared to control.

Conclusion: Supplementation with black pepper extract, coffee extract, and a mixture of both significantly improved these findings. In conclusion, black pepper and coffee extracts are overlooked as promising weight reduction and antihyperlipidemic agents.

Keywords: Energy homeostasis, Obesity, Black pepper extract, Coffee extract, Cyclic adenosine monophosphate, Neurotransmitters.

(C) 2016 The Authors. Published by Innovare Academic Sciences Pvt Ltd. This is an open access article under the CC BY license (http://creativecommons. org/licenses/by/4. 0/) DOI: http://dx.doi.org/10.22159/ajpcr.2016.v9s3.14592

\section{INTRODUCTION}

Energy homeostasis is referred to as the equilibrium between energy intake including food and drinks intake and energy expenditure including physical activity in adults over a long period and resting energy expenditure (basal metabolism) [1].

Obesity results from the imbalance between energy expenditure and intake leading to increase gain in bodyweight and accumulation of fats in the body [2]. Various feedback mechanisms regulate appetite, energy intake, and expenditure to maintain energy homeostasis. When these feedback mechanisms are altered, energy balance is disturbed and body adiposity became unstable [1].

Triton WR-1339, is a non-ionic detergent (oxyethylated tertiary octylphenol formaldehyde polymer), used to induce acute obesity by inhibiting lipoprotein lipase activity blocking plasma lipolytic activity resulting in increased blood lipid concentration. Furthermore, it has been used for screening chemical and natural hypolipidemic drugs, studying lipid metabolism, and investigating the metabolic interrelationship between blood lipoproteins $[3,4]$.

Numerous studies showed that diet-induced obesity leads to insulin resistance accompanied with obesity that is mainly due to the presence of inflammation [5,6].

Cortez et al. [7] documented that high-fat diet (HFD) leads to chronic overweight and obesity, as well as enhancing chronic inflammation associated with increased free fatty acids (FFAs) and high adipose and serum levels of inflammatory mediators such as tumor necrosis factor- $\alpha$ (TNF- $\alpha$ ), interleukin-1 (IL-1), IL-6, and necrotic factor- $\kappa B$ $(\mathrm{NF}-\kappa \mathrm{B})$. These cytokines are regulated by cAMP activity which enhances adipocyte differentiation [8].
Cyclic adenosine monophosphate (cAMP, cyclic AMP, or 3'-5'-cyclic adenosine monophosphate) is a second messenger important in many biological processes $[9,10]$. cAMP plays an important role in glucose homeostasis, energy balance, and lipid metabolism by mediating stress and hunger signaling through adrenalin and glucagon receptors. It is considered a key regulator in energy homeostasis which is involved in many biochemical processes in all tissues of the body. Many hormones such as vasopressin, dopamine, serotonin, norepinephrine (NE), histamine, or prostacyclin are regulated by cAMP [11].

Chemical treatments as well as surgical interventions are not always appropriate as they provide short-term benefits in obesity, but unfortunately, it is often accompanied with rebound weight gain after treatment cessation, numerous side effects, and the susceptibility for drug abuse [12]. Current science depends on the safety and efficacy of medicinal plants besides their useful effects in many disease states such as hyperlipidemia, obesity, and diabetes mellitus mainly due to their antioxidant effects [13].

Coffee is one of the most commonly consumed beverages worldwide. The two most common sources of coffee beans are Coffee arabica and Coffee canephora (robusta). Regular coffee is rich in bioactive compounds and possesses antioxidant, hypoglycemic, anticarcinogenic, anti-inflammatory, antimicrobial, and hepatoprotective effects [14].

Black pepper (Piper nigrum) possesses a number of therapeutic effects in hepatitis, rheumatoid arthritis, colic hemorrhoids, and as antidiabetic agent besides its influence on lipid metabolism, antioxidant, and antihepatotoxic activities [15]. Piperine (1-piperoyl piperidine), the active constituent in black pepper, is responsible for its therapeutic activities [16] such as antitumor, antimutagenic, and immunomodulatory properties [17]. 
From this prospective, this study aimed to evaluate the effect of black pepper and coffee aqueous extracts on chronic and acute experimentalinduced obesity and energy homeostasis.

\section{MATERIALS AND METHODS}

\section{Materials}

NE, dopamine, and serotonin standards (high-performance liquid chromatography [HPLC] grade) and triton WR-1339 (tyloxapol) were purchased from Sigma-Aldrich medical company (Sigma, St. Louis, USA). Cholesterol and bile salts were obtained from the El-Gomhoria Company for chemical and medical equipment, El-Ameyria, Cairo, Egypt. Coffee bean powder and black pepper seeds (P. nigrum) were purchased from local market.

\section{Experimental animals}

Male albino rats weighting 180-200 g were obtained from the animal house of the National Research Centre, Giza, Egypt. Animals were housed in individual suspended stainless steel cages in a controlled environment $\left(22-25^{\circ} \mathrm{C}\right)$ and $12 \mathrm{hr}$ light, $12 \mathrm{hr}$ dark. The animals had free access to water and standard rodent chow diet. All animals received human care in compliance with guidelines of the Ethical Committee of National Research Centre, Egypt, and followed the recommendations of the National Institutes of Health Guide for Care and Use of Laboratory Animals.

\section{Methods}

\section{Preparation alcoholic extract of $P$. nigrum}

Alcoholic extract of $P$. nigrum was carried out according to Rasheed et al. [18]. The seeds of $P$. nigrum were grounded by mill into the fine powder. $100 \mathrm{~g}$ of $P$. nigrum powder was macerated in $500 \mathrm{ml}$ of $70 \%$ methanol and left at room temperature for 3 days, and then filtered by Whatman No. 1 filer paper. The residue was repeatedly extracted with fresh methanol until the extraction solvents became colorless. The combined filtrates were evaporated under reduced pressure at $45^{\circ} \mathrm{C}$ in a rotatory evaporator (Heidolph, Germany) till dryness. The yield of dry extract was $1.7 \mathrm{~g} \%$ for P. nigrum [19] and dissolved in distilled water for preparation of aqueous extract.

\section{Preparation of coffee aqueous extract}

About $40 \mathrm{~g}$ powdered dark coffee beans was dissolved in $100 \mathrm{ml}$ of distilled water boiled at $100^{\circ} \mathrm{C}$ for 5 minutes, then filtered by Whatman No. 1 filter paper to obtain filtered coffee extract [20]. The yield of aqueous extract was $1.75 \mathrm{ml}$ per $1 \mathrm{~g}$ of coffee powder used.

\section{Induction of obesity}

\section{Induction of chronic obesity by HFD}

Obesity was induced by feeding rats with HFD daily for 3 months. HFD consisted of normal laboratory diet (NLD) in powder form mixed with (30\%) melted animal abdominal fat (beef tallow), extra pure cholesterol (2\%), and bile salt (1.5\%) to enhance the internal absorption of lipids [21]. After 12 weeks, rats were kept fasting overnight, and blood was collected to confirm hyperlipidemia.

\section{Induction of obesity by triton-1339 (tyloxapol) and HFD}

Rats were fed on HFD daily for 12 weeks and were injected i.p. with triton WR-1339 (300 mg/kg b.w.) dissolved in 0.9\% saline; 3 times/week for 3 weeks of the starting from week 10 till the end of week 12, with 2 days intervals between injections [22]. After 12 weeks, blood was collected to confirm hyperlipidemia.

\section{Induction of acute obesity}

Rats (150-190 g weight) feeding on NLD, kept fasting overnight and injected i.p. with a single dose $300 \mathrm{mg} / \mathrm{kg}$ b.w. $1 \mathrm{hr}$ following triton injection, the animals were allowed to feed. Then, kept fasting for $24 \mathrm{hr}$ and blood was collected and plasma was separated for further biochemical assays [23].

\section{Experimental design}

Around 80 male albino rats were divided into 10 groups (8 rats in each group).

Group I (Normal control): Healthy rats fed on NLD.

Group II (HFD group): Normal rats fed on HFD diet for 16 weeks.

Group III (HFD+Black pepper extract): Obese rats received $0.5 \mathrm{ml}$ of black pepper extract (375 mg/kg b.w./day) orally for 4 weeks [24].

Group IV (HFD+Coffee extract): Obese rats received $0.35 \mathrm{ml}$ extract/100 g b.w. of coffee extract (2 g/kg b.w./day) orally for 4 weeks [20].

Group V (HFD+Mixture): Obese rats received mixture of $0.35 \mathrm{ml}$ extract/100 g b.w. of coffee extract ( $2 \mathrm{~g} / \mathrm{kg}$ b.w./day) and $0.5 \mathrm{ml}$ of black pepper extract (375 mg/kg b.w./day) orally for 4 weeks.

Group VI (Triton+HFD): Obese rats i.p. injected with triton $(300 \mathrm{mg} / \mathrm{kg}$ b.w.) and received normal saline ( $1 \mathrm{ml} / \mathrm{kg} \mathrm{b.w./day)} \mathrm{orally} \mathrm{for} 4$ weeks.

Group VII (Triton+HFD+Black pepper): Obese rats i.p. injected with triton $(300 \mathrm{mg} / \mathrm{kg}$ b.w.) and received $0.5 \mathrm{ml}$ of black pepper extract (375 mg/kg b.w./day) orally for 4 weeks.

Group VIII (Triton+HFD+Coffee): Obese rats i.p. injected with triton (300 mg/kg b.w.) and received $0.35 \mathrm{ml}$ extract/100g b.w. of coffee extract ( $2 \mathrm{~g} / \mathrm{kg}$ b.w./day) orally for 4 weeks.

Group IX (Triton+HFD+Mixture): Obese rats i.p. injected with triton (300 mg/kg b.w.) and received mixture of $0.35 \mathrm{ml}$ extract/100 g b.w. of coffee extract ( $2 \mathrm{~g} / \mathrm{kg}$ b.w./day) and $0.5 \mathrm{ml}$ of black pepper extract (375 mg/kg b.w./day) orally for 4 weeks.

Group X (Triton group): Healthy rats fed on NLD injected i.p. with triton at a dose of $300 \mathrm{mg} / \mathrm{kg}$ b.w. once at the end of the experiment to induce acute obesity [23].

After the experimental period (16 weeks), blood was withdrawn from the retro-orbital venous plexus of the eye using capillary tubes and collected in tubes contain a-sodium fluoride for blood glucose estimation and b-tubes contain anticoagulant for other biochemical analysis.

Brain was removed quickly and placed in iced normal saline, perfused with normal saline solution to remove blood cells, blotted on filter paper, and frozen at $-80^{\circ} \mathrm{C}$. The frozen tissues were cut into small pieces and homogenized in $5 \mathrm{ml}$ cold buffer $\left(0.5 \mathrm{~g}\right.$ of $\mathrm{Na}_{2} \mathrm{HPO}_{4}$ and $0.7 \mathrm{~g}$ of $\mathrm{NaH}_{2} \mathrm{PO}_{4}$ per $500 \mathrm{ml}$ deionized water $(\mathrm{pH} 7.4$ ) per gram tissue, then centrifuged at $4000 \mathrm{rpm}$ for 15 minutes at $4^{\circ} \mathrm{C}$, the supernatant was removed for brain cAMP estimation [25].

Fasting blood sugar was estimated by colorimetric method using commercial kit purchased from Vitro Scient, Egypt, based on the method described previously [26]. Liver and kidney functions were determined by commercial kits according to the methods described by Reitman and Frankel [27], Kaplan [28], and Fabiny and Ertinghausen [29]. Lipid profile was estimated colorimetric methods according to the methods described previously. Total cholesterol (TC) [30], triglycerides (TG) [31], high-density lipoprotein (HDL) [32], and all kits were purchased from BioMed Diagnostics.

Low-density lipoprotein-cholesterol (LDL-C) was calculated from the following formula:

LDL-cholesterol=Total cholesterol-(HDL-C+TG/5)=LDL according to Friedwald et al. [32]. $(\mathrm{mg} / \mathrm{dl})$ 
Very low-density lipoprotein cholesterol (VLDL-C) was calculated using the following equation:

$\operatorname{VLDL}-\mathrm{C}(\mathrm{mg} / \mathrm{dL})=\mathrm{TG} / 5$

Plasma insulin level was estimated by enzyme-linked immunosorbent assay (ELISA) according to Yalow and Bauman [33] using BioSoure INSEASIA Kit. Insulin resistance was calculated from the equation:

Insulin resistance=Fasting glucose $(\mathrm{mg} / \mathrm{dl}) \times$ Fasting insulin $(\mu \mathrm{IU} / \mathrm{ml}) / 405$ according to Matthews et al. [34].

Brain and serum cAMP was measured by ELISA according to Yalow and Bauman [35] using Kit purchased from Glory Science Co., Ltd, USA.

\section{Determination of brain neurotransmitters}

Determination of brain NE, dopamine, and serotonin was carried out as described previously by Hussein et al. [36] using HPLC system, Agilent Technologies 1100 series, equipped with a quaternary pump (G131A model).

Separation was achieved on ODS-reversed phase column (C18, $25 \times 0.46 \mathrm{~cm}$ i.d. $5 \mu \mathrm{m}$ ). The mobile phase consisted of potassium phosphate buffer/methanol $97 / 3(\mathrm{v} / \mathrm{v})$ and was delivered at a flow rate of $1.5 \mathrm{ml} /$ minutes. UV detection was performed at $270 \mathrm{~nm}$, and the injection volume was $20 \mu \mathrm{l}$.

The concentration of both catecholamines and serotonin was determined by external standard method using peak areas. Serial dilutions of standards were injected, and their peak areas were determined. A linear standard curve was constructed by plotting peak areas versus the corresponding concentrations of each standard. The concentration in samples was obtained from the curve.

\section{The histopathological study}

The liver was dissected out and fixed instantaneously in 10\% formal saline for $24 \mathrm{hrs}$. The specimens were washed in tap water, dehydrated in ascending grades of ethanol, cleared in xylene, embedded in paraffin wax (melting point $58-60^{\circ} \mathrm{C}$ ). Paraffin sections of $6 \mu \mathrm{m}$ thicknesses were prepared and stained with hematoxylin and eosin [37] for histopathological examination.

\section{Statistical analysis}

All data were expressed as mean \pm standard error. Data were analyzed using one-way ANOVA using SPSS (Version 16). Duncan's new multiplerange test was used to assess differences between means. Pearson's correlation test was used to assess correlations between means. A significant difference was considered at the level of $\mathrm{p}<0.05$.

\section{RESULTS AND DISCUSSION}

In this study, the mean values of blood glucose and insulin were significantly increased in HFD and triton groups compared to control (Table 1), this may be due to hyperlipidemia and increased amount of FFA which directly affect insulin signaling, diminish glucose uptake in muscles and adipose tissue, drive exaggerated triglyceride synthesis, and induce gluconeogenesis in the liver leading to elevated levels of glucose and lipids which may lead to type-2 diabetes, insulin resistance, and metabolic syndrome.

Furthermore, insulin inhibits cAMP signaling by activation of phosphodiesterase as insulin and cAMP signaling play significant roles in sensing energy balance in two opposite ways, in which insulin is associated with food availability and promotes processes of food storage such as glucose uptake, lipogenesis, and glycogen synthesis. On the other hand, cAMP signaling is associated with nutrition deprivation, promoting release of stored energy by activation of lipolysis and glycogen degradation associated with glucagon and adrenalin stimulation [38].

The present data showed that HFD fed rats had a significant increase in feed efficiency ratio, body mass index (BMI), and

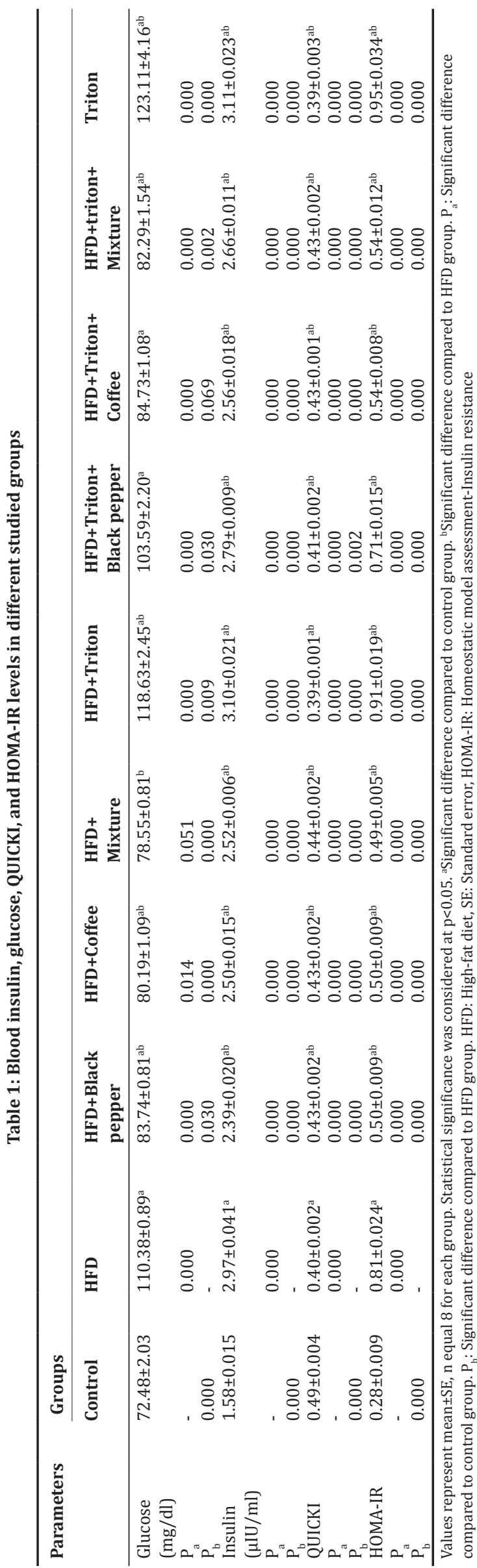


body weight gain (BWG)\% compared with control group (Table 2). These results agree with Ismail et al. [39], who reported that longterm feeding with HFD had high calories and high energy intake which led to accumulation of increased fats in body, especially in adipose tissues leading to obesity, insulin resistance, liver injury, and atherosclerosis. Moreover, this redirects fatty acids to the liver enhancing hyperlipidemia [40].

In the current study, the mean values of liver and kidney functions were significantly increased in HFD and triton groups compared to control (Table 3). These results agree with Ismail et al. [39], suggesting that the hyperlipidemia, abnormal lipid metabolism, and increased fatty acids lead to liver injury such as non-alcoholic fatty liver and hepatic steatosis as well as renal injury.

These results were also confirmed by histopathological study where the hepatic lobules, the structural units of the liver (Fig. 1a), and portal areas (Fig. 1b) of control rats show the normal structure, whereas microscopic examination liver sections of obese rats showed lymphocytic infiltration in the portal and periportal areas. The dilated sinusoids were also noticed (Fig. 1c). Other sections showed microvesicular and macrovesicular patterns of fatty infiltration (Fig. 1d). In some rats, disturbance of the hepatic architecture associated with foci of hepatocytes necrosis was seen (Fig. 1e), focal necrosis of the hepatocytes associated with lymphocytic infiltration, the presence of cell debris in the blood sinusoids, some hyperchromatic and pyknotic nuclei was also seen (Fig. 1f).

These results were accompanied with a significant increase in serum TG, TC, LDL, and VLDL in HFD- and triton-induced obesity groups compared to control group, concomitant with a significant increase of HDL in obese groups compared to control (Table 4). This may be due to triton WR-1339 is known to induce hyperlipidemia in two phases: Phase I in which there is an increased hepatic cholesterol biosynthesis through triton's interference with the tissue uptake of plasma lipids, whereas Phase II involves triton's interference with cholesterol excretion and metabolism [41], in the same line, in HFD models, hyperlipidemia is induced when dietary lipid including cholesterol inhibits FA oxidation and LDL cholesterol uptake [4].

Our results showed that induction of obesity by HFD and triton significantly increased brain cAMP levels in obese groups compared to control (Table 5). These are supported by the suggestion of Sahu et al. [42] that some variants in melanocortin 4 receptors (MC4R) and hypothalamic leptin resistance and high-leptin level in brain of obese leading to accumulation of intracellular cAMP and this explain the high level of brain cAMP. Furthermore, high-leptin levels in obese brain lead to failure to activate PDE3B which is required for lowering intracellular cAMP level. Contrarily, serum cAMP levels were decreased in obese groups when compared to control group. These results were in agreement with Ohyama et al. [43], who reported that the serum level of cAMP in obese was significantly lower than the non-obese rats. This may be due to the increase of FFAs and increased serum levels of mediators such as TNF- $\alpha$, IL-1, IL-6, and $\mathrm{NF}-\kappa \mathrm{B}$ and reduced peroxisome proliferator-activated receptor gamma expression, resulting in overall decrease of serum cAMP [6].

Furthermore, Li et al. [44] study reported that the serum level of brainderived neurotrophic factor is low in obesity that may be due to low serum cAMP in obese.

The present study revealed that the level of brain NE and dopamine had a significant increase in HFD group, HFD+triton group, and triton group when compared with the control group. The level of brain serotonin was significantly increased in HFD group concomitant with a significant decrease in HFD+triton group and triton group when compared with control group (Table 6).

These findings agree with Gotthardt et al. [45], who showed that obese rats feeding on high-caloric diets had high significant brain NE

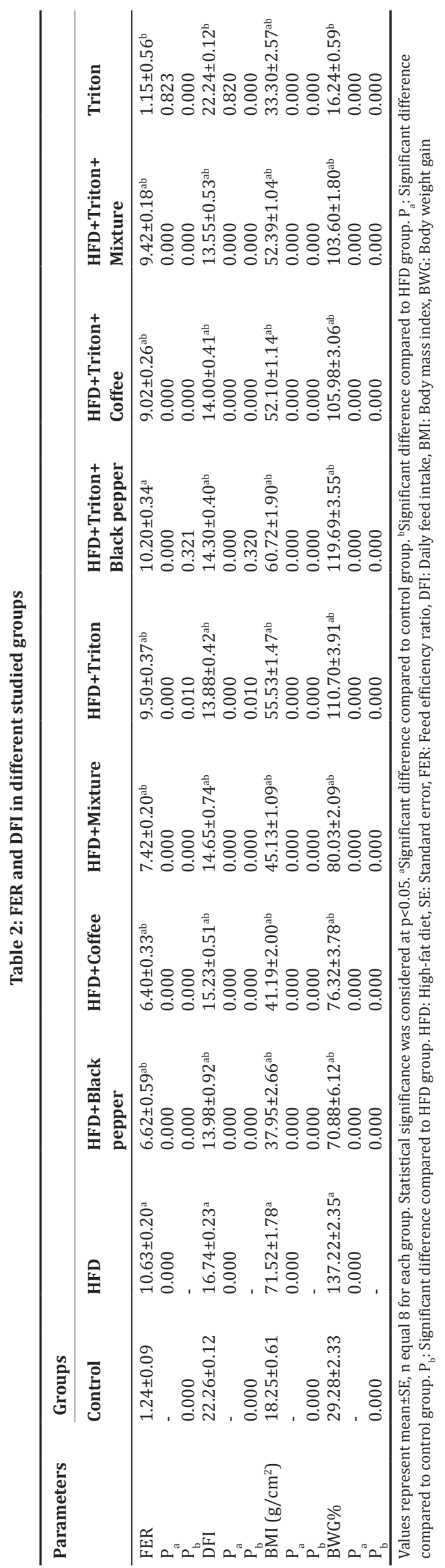




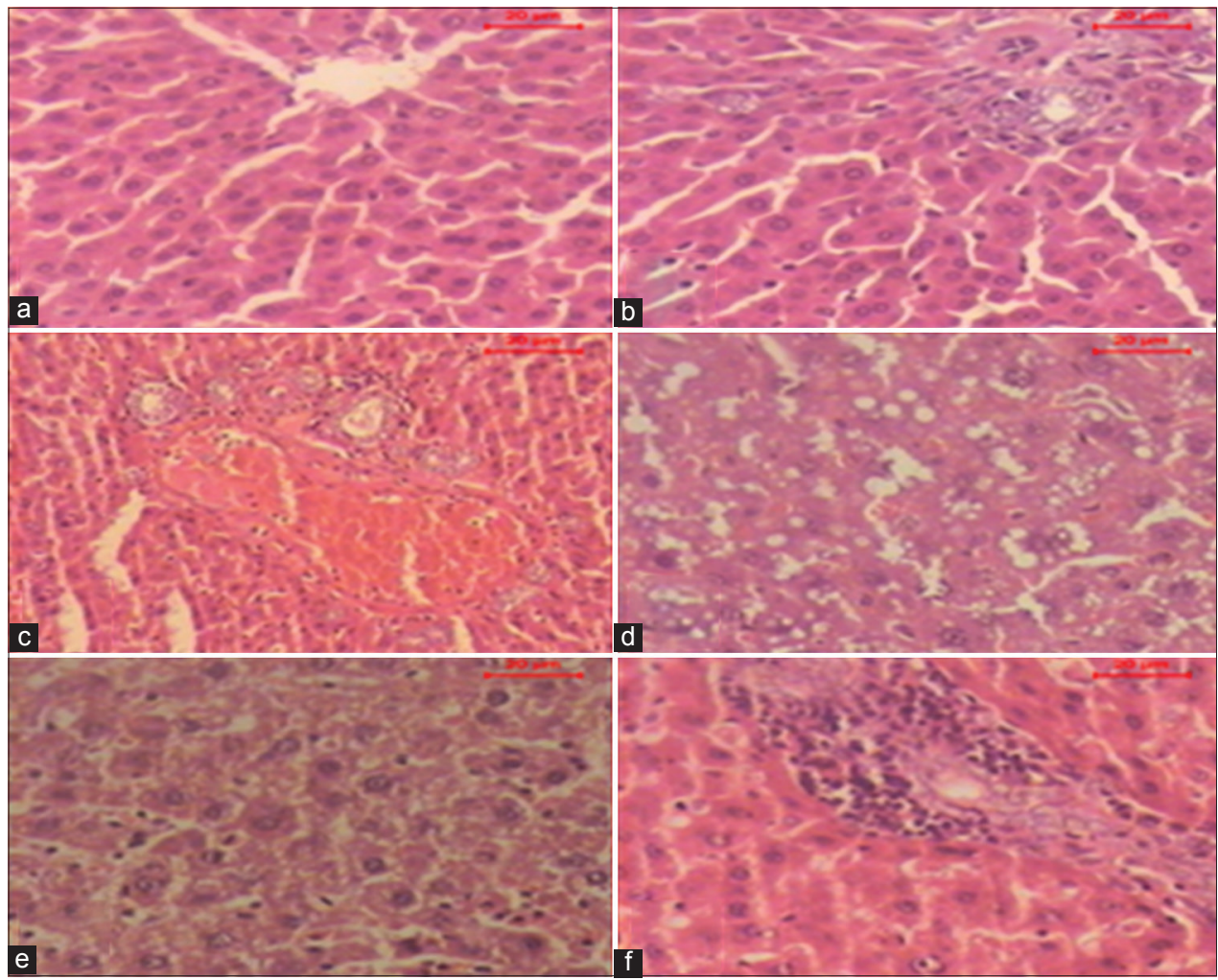

Fig. 1: Sections of liver of (a and b) control rat shows the normal architecture of the hepatic lobule and portal tract, respectively, (c) obese rat shows lymphocytic infiltration in the portal and periportal areas and dilated sinusoids, (d) obese rat shows a microvesicular and microvesicular pattern of fatty infiltration, (e) obese rat shows a disturbance of the hepatic architecture associated with foci of hepatocytes necrosis, (f) obese rat shows a focal necrosis of the hepatocytes associated with lymphocytic infiltration, the presence of cell debris in the blood sinusoids and some nuclei hyperchromasia and pyknosis ( $\mathrm{H}$ and E. stain, Scale bar: $20 \mu \mathrm{m}$ )

than normal weight rats due to increased NE turnover in peripheral tissues and elevated resting plasma NE levels. Moreover, high NE in obese eliciting recruitment of BAT, including both increased and overexpression of UCP1 levels leading to hypertrophy and hyperplasia of BAT which results in cardiovascular disorders. Furthermore, these studies investigated a positive correlation between glucose and NE.

Contrarily, Jabbour et al. [46] disagree with our findings in the present study stating that obesity is associated with low sympathetic nervous activity and low brain NE concentration than normal control, leading to reduce thermogenesis and increased weight gain.

Dopamine levels are elevated in the brains of obese due to increased expression of Dopamine 1 receptor and its down regulator cAMPregulated phosphoprotein of $32 \mathrm{KDa}$ (DARPP 32), resulting in increased cAMP-PKA pathway [47]. In the same line, Carlin et al. [48] suggested that obesity is associated with decreased expression of genes involved in availability of dopamine leading to weight gain.

Serotonin levels were significantly increased in obese rats when compared to control. Meanwhile, treating obesity by inhibiting serotonin synthesis and peripheral serotonin where obesity is associated with high brain and peripheral 5-HT than normal control and pharmacological "enzyme blocker," blocking the production of peripheral serotonin makes the brown fat more active $[49,50]$. From the present study, as triton caused the opposite effect on serotonin from HFD only induced obesity, this suggested that hyperlipidemia may have more different pathways that affected serotonin.

On the other hand, treatment with black pepper, coffee, and their mixture improve the serum glucose, insulin, and insulin resistance (Table 1), these results agree with Rezq and Fathy and Aziz et al. [20,41], who suggested that black pepper and coffee decreased glucose and insulin and may reduce risk of type 2 diabetes as they decrease the oxidative stress. Furthermore, coffee improves blood glucose level and glucose homeostasis which may be due to the inhibition of adenosine receptors that activate cyclic AMP-dependent protein kinase [51]. In addition, chlorogenic acid present in coffee acts as a competitive inhibitor on glucose absorption in the intestine [52].

Treatment with black pepper, coffee, and their mixture improved (FER, BMI, and BWG\%) and feed intake (Table 2), these results agree with Chioma et al. and Huang et al. [53,54], who demonstrated that black pepper and coffee increase lipolysis, and thus, stimulates thermogenesis and energy expenditure which leads to a weight reduction.

Supplementation with black pepper, coffee, and their mixture improve the serum ALT, AST (except for coffee + triton group), and kidney urea and creatinine levels (Table 3 ) and these results agree with Huang et al. [54], who stated that coffee may decrease hepatic fatty acid synthesis recovering $\beta$-oxidation and reducing lipid peroxidation which further reduces liver enzymes, hepatic steatosis and protect from hepatic injury [55]. However, the opposite effect showed in rats injected with triton as showed high-serum AST than HFD group and this agrees with Rezq and Fathy [20], who suggested that the high-serum AST caused by coffee due to the presence of cafestol and kahweol in coffee that raise the serum concentration of AST and ALT.

These findings were confirmed by histopathology where the histopathological investigation of liver sections of obese rats treated with black pepper showed the architecture of the hepatic lobules appeared more or less like normal (Fig. 2a). A micrograph of a liver section of obese rats injected with triton and treated with black pepper showed the normal hepatic lobules structure (Fig. 2b).

Histopathological examination of liver sections of obese rats treated with coffee showed normal hepatic lobules structure associated with few microvesicular patterns of fatty infiltration (Fig. 2c). In some 

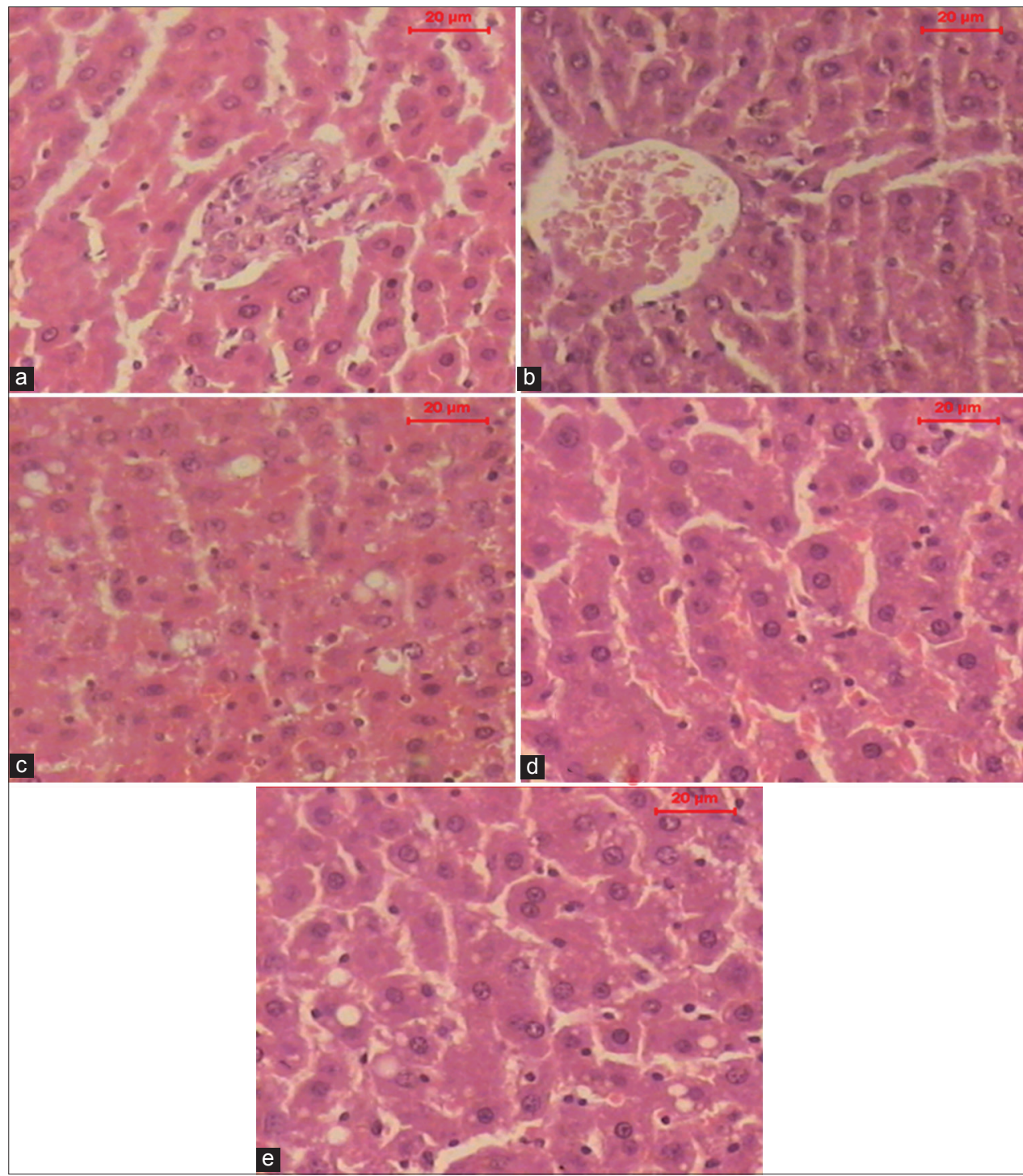

Fig. 2: A micrograph of a liver section of (a) Obese rat treated with black pepper shows the architecture of the hepatic lobule that appears more or less like normal. (b) A micrograph of a liver section of obese rat injected with triton and treated with black pepper shows the normal hepatic lobule structure. (c) A micrograph of a liver section of obese rat treated with coffee shows the normal hepatic lobule structure. Notice few microvesicular pattern of fatty infiltration. (d) A micrograph of a liver section of obese rat injected with triton and treated with coffee shows the normal hepatic lobule structure. Notice the congested hepatic sinusoids. (e) A micrograph of a liver section of obese rat injected with triton and treated with coffee shows the normal hepatic lobule structure. Notice few macrovesicular pattern of fatty infiltration (H and E, stain, Scale bar: $20 \mu \mathrm{m}$ )

rats, sections of obese rat injected with triton and treated with coffee showed the normal hepatic lobule structure and congested hepatic sinusoids (Fig. 2d). Micrographs of liver sections of obese rat injected with triton and treated with coffee showed the normal hepatic lobule structure. Few macrovesicular patterns of fatty infiltration were noticed (Fig. 2e)

The mean values of lipid profile were significantly changed after treatment with both black pepper extract and coffee extract and their mixture when compared to HFD, HFD+triton, triton, and control groups (Table 4). These results agree with Chioma et al. and Huang et al. [53,54], who revealed that black pepper and coffee stimulate lipid metabolism and fat mobilization from adipose tissue leading to decrease in FFAs and hepatic lipids and increase the thermogenic response and energy expenditure.

In the present study, supplementation with black pepper, coffee extract, and their mixture significantly changed the mean levels of cAMP in treated groups when compared to obesity-induced groups with both HFD and triton (Table 5). Coffee is phosphodiesterases inhibitor that inhibits and blocks adenosine receptors induce lipolysis by increasing cAMP [56]. Furthermore, piperine is used as an MC4R agonist increasing cAMP resulting in a reduction in food intake [57].

These results agree with Yoon et al. [16], who suggested that coffee and black pepper increase serum cAMP and suggested to be good therapies as antiobesity treatment as well as the rise in cAMP was accompanied by the decrease in the secretion of triacylglycerol, cholesterol, and apolipoprotein B via VLDL [58].

Coffee as phosphodiesterases inhibitor inhibited adenosine receptor leading to increases NE, dopamine levels, and serotonin [59]. Moreover, black pepper and its main component piperine led to increased $\mathrm{NE}$, dopamine, and serotonin levels [60], resulted in the inhibition of food intake and decreasing body weight by stimulating thermogenesis and energy expenditure through the sympathetic nervous system. 

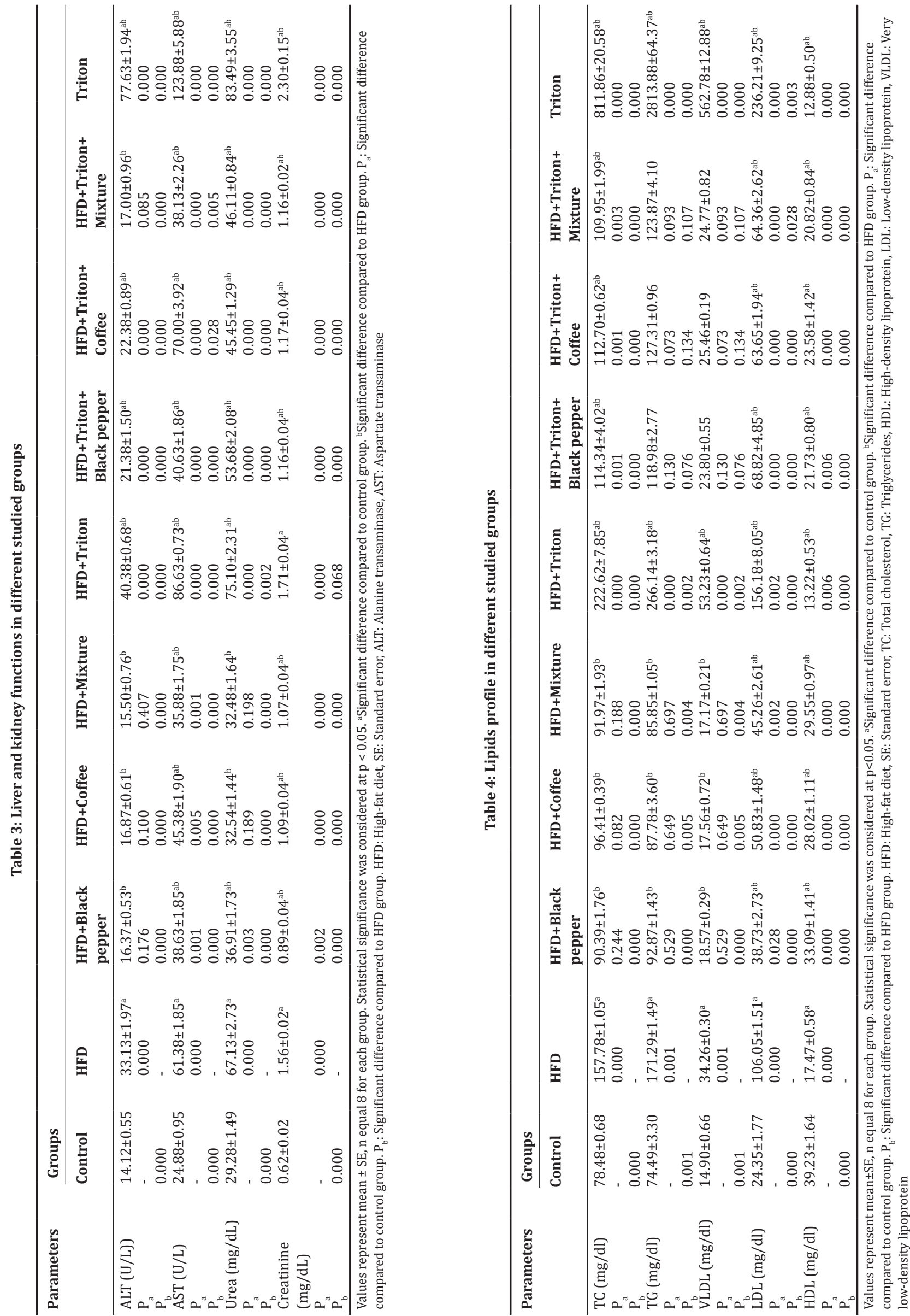

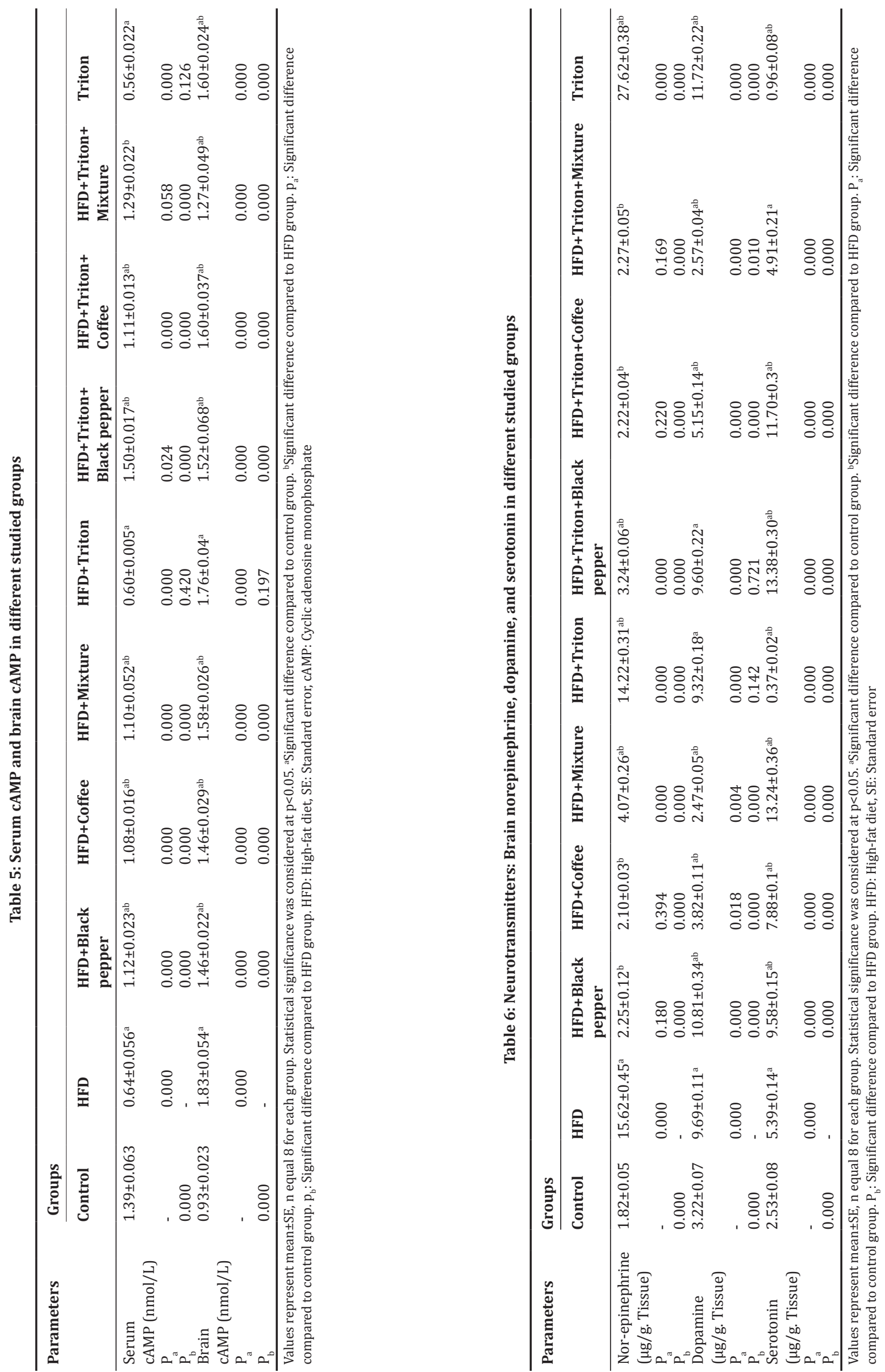


\section{CONCLUSION}

In conclusion, black pepper and coffee extracts are overlooked as promising weight reduction and antihyperlipidemic agents. Their effects might be attributed to their antioxidant activities as well as their impact on brain levels of cAMP and neurotransmitters resulting in reduction of food intake and stimulation of thermogenesis. Thus, lowering body weight and decreasing fat accumulation throughout the body.

\section{ACKNOWLEDGMENT}

Authors are grateful to the National Research Centre, Cairo, Egypt, for unlimited help and support to carry out this work.

\section{REFERENCES}

1. Guyenet SJ, Schwartz MW. Clinical review: Regulation of food intake, energy balance, and body fat mass: Implications for the pathogenesis and treatment of obesity. J Clin Endocrinol Metab 2012;97(3):745-55.

2. Ebbert JO, Jensen MD. Fat depots, free fatty acids, and dyslipidemia. Nutrients 2013;5(2):498-508.

3. Aziz N, Mehmood MH, Siddiqi HS, Mandukhail SU, Sadiq F, Maan W, et al. Antihypertensive, antidyslipidemic and endothelial modulating activities of Orchis mascula. Hypertens Res 2009;32:997-1003.

4. Adeneye AA, Crooks PA. Weight losing, antihyperlipidemic and cardioprotective effects of the alkaloid fraction of Hunteria umbellata seed extract on normal and triton-induced hyperlipidemic rats. Asian Pac J Trop Biomed 2015;5(5):387-94.

5. Gregor MF, Hotamisligil GS. Inflammatory mechanisms in obesity. Annu Rev Immunol 2011;29:415-45.

6. Benzler J, Ganjam GK, Pretz D, Oelkrug R, Koch CE, Legler K, et al. Central inhibition of IKKß/NF-?B signaling attenuates high-fat dietinduced obesity and glucose intolerance. Diabetes 2015;64(6):2015-27.

7. Cortez M, Carmo LS, Rogero MM, Borelli P, Fock RA. A high-fat die increases IL-1, IL-6, and TNF-a production by increasing NF-?B and attenuating PPAR-? expression in bone marrow mesenchymal stem cells. Inflammation 2013;36(2):379-86.

8. Guri AJ, Hontecillas R, Bassaganya-Riera J. Abscisic acid synergizes with rosiglitazone to improve glucose tolerance and down-modulate macrophage accumulation in adipose tissue: Possible action of the cAMP/PKA/PPAR ? Axis. Clin Nutr 2010;29(5):646-53.

9. Zhang C, Wang G, Zheng Z, Maddipati KR, Zhang X, Dyson G, et al. Endoplasmic reticulum-tethered transcription factor cAMP responsive element-binding protein, hepatocyte specific, regulates hepatic lipogenesis, fatty acid oxidation, and lipolysis upon metabolic stress in mice. Hepatology 2012;55(4):1070-82.

10. Langeberg LK, Scott JD. Signalling scaffolds and local organization of cellular behaviour. Nat Rev Mol Cell Biol 2015;16(4):232-44.

11. Yan J, Mei FC, Cheng H, Lao DH, Hu Y, Wei J, et al. Enhanced leptin sensitivity, reduced adiposity, and improved glucose homeostasis in mice lacking exchange protein directly activated by cyclic AMP isoform 1. Mol Cell Biol 2013;33(5):918-26.

12. Hasani-Ranjbar S, Larijani B. Medicinal plants as potential new target drugs in endocrine disorders - Review article. Iran J Publ Health 2014;43(1):24-34

13. Hasani-Ranjbar S, Jouyandeh Z, Abdollahi M. A systematic review of anti-obesity medicinal plants - An update. J Diabetes Metab Disord 2013;12(1):28

14. Panza F, Solfrizzi V, Barulli MR, Bonfiglio C, Guerra V, Osella A, et al. Coffee, tea, and caffeine consumption and prevention of late-life cognitive decline and dementia: A systematic review. J Nutr Health Aging 2015;19(3):313-28

15. Bai X, Zhang W, Chen W, Zong W, Guo Z, Liu X. Antihepatotoxic and antioxidant effects of extracts from Piper nigrum L. root. Afr J Biotechol 2011;10(2):267-72.

16. Yoon YC, Kim SH, Kim MJ, Yang HJ, Rhyu MR, Park JH. Piperine, a component of black pepper, decreases eugenol-induced cAMP and calcium levels in non-chemosensory 3T3-L1 cells. FEBS Open Bio 2014:5:20-5.

17. Do MT, Kim HG, Choi JH, Khanal T, Park BH, Tran TP, et al. Antitumor efficacy of piperine in the treatment of human HER2-overexpressing breast cancer cells. Food Chem 2013;141(3):2591-9.

18. Rasheed M, Afshan F, Tariq RM, Siddiqui BS, Gulzar T, Mahmood A, et al. Phytochemical studies on the seed extract of Piper nigrum Linn. Nat Prod Res 2005;19(7):703-12.
19. Mahdy K, Shaker O, Wafay H, Nassar Y, Hassan H, Hussein A. Effect of some medicinal plant extracts on the oxidative stress status in Alzheimer's disease induced in rats. Eur Rev Med Pharmacol Sci 2012;16(13):31-42.

20. Rezq AA, Fathy NM. Effect of regular drinking of boiled, filtered or Turkish coffee and its impact on some biochemical parameters relevant to atherogenicity and the functions of the kidney and the liver in rat model. Eur J Sci 2010;2(3):46-54.

21. Gupta S, Kaushik M. Histomorphologicl and hypolipidaemic effects from whole plant of Gymenma sylvestre in high cafeteria diet-induced obese rat model. J Pharm Biomed Sci 2010;2(2):1-9.

22. Levine S, Saltzman A. A procedure for inducing sustained hyperlipemia in rats by administration of a surfactant. J Pharmacol Toxicol Methods 2007;55:224-6.

23. Mishra R, Pandit K, Bhawat AM, Brijesh S. Antihyperlipidemic activity of alcoholic extracts of Trichosanthes anguina in triton $\mathrm{Wr}$ 1339 induced hyperlipidemic rats. IJPSR 2014;5(10):4269-74.

24. Ahmed HA, Salem MH, Sabry GM, Husein HA, Kotob SE. New insights in the horizon for the treatment of Alzheimer's disease: A proposal based on experimental study. Der Pharm Lett 2015;7(2):165-82.

25. Mannaa F, Ahmed HH, Estefan SF, Sharaf HA, Eskander EF. Saccharomyces cerevisiae intervention for relieving flutamide-induced hepatotoxicity in male rats. Pharmazie 2005;60:689-95.

26. Trinder P. Determination of blood glucose using an oxidaseperoxidase system with a non-carcinogenic chromogen. J Clin Pathol 1969;22(2):158-61

27. Reitman S, Frankel S. A colorimetric method for the determination of serum glutamic oxalacetic and glutamic pyruvic transaminases. Am J Clin Pathol 1957;28(1):56-63.

28. Kaplan A. Urea. In: Kaplan LA, Pesce AJ, editors. Clinical Chemistry: Theory, Analysis and Correlation. St. Louis, Miss.: Mosby; 1984 p. 1257-60.

29. Fabiny DL, Ertinghausen G. Automated reaction-rate method for determination of serum creatinine with the Centrifuge. Clin Chem 1971;17(8):696-700.

30. Meiattini F, Prencipe L, Bardelli F, Giannini G, Tarli P. The 4-hydroxybenzoate/4-aminophenazone chromogenic system used in the enzymic determination of serum cholesterol. Clin Chem 1978;24(12):2161-5.

31. Bucolo G, David H. Quantitative determination of serum triglycerides by the use of enzymes. Clin Chem 1973;19(5):476-82.

32. Friedewald WT, Levy RI, Fredrickson DS. Estimation of the concentration of low-density lipoprotein cholesterol in plasma, without use of the preparative ultracentrifuge. Clin Chem 1972;18(6):499-502.

33. Yalow R, Bauman WA. Insulin in health and disease. In: Ellenberg M, Rifkin H, editors. Diabetes Mellitus: Theory and Practice. New York: Excerpta Medica; 1983. p. 119-50.

34. Matthews DR, Hosker JP, Rudenski AS, Naylor BA, Treacher DF, Turner RC. Homeostasis model assessment: Insulin resistance and betacell function from fasting plasma glucose and insulin concentrations in man. Diabetologia 1985;28(7):412-9.

35. McDaniel FK, Molden BM, Mohammad S, Baldini G, McPike L, Narducci P, et al. Constitutive cholesterol-dependent endocytosis of melanocortin-4 receptor (MC4R) is essential to maintain receptor responsiveness to $\alpha$-melanocyte-stimulating hormone $(\alpha-\mathrm{MSH})$. J Biol Chem 2012;287(26):21873-90.

36. Hussein J, Abo EL-Matty D, El-Khayat Z, Abdel-Latif Y. Brain neurotransmitters in diabetic rats treated with coenzyme Q10. Int J Pharm Pharm Sci 2012;4 Suppl 4:554-6.

37. Drury RA, Wallington EA. Carleton's Histological Technique. $4^{\text {th }}$ ed. Oxford: Oxford University Press; 1980.

38. Manmontri B, Sariahmetoglu M, Donkor J, Bou Khalil M, Sundaram M, Yao Z, et al. Glucocorticoids and cyclic AMP selectively increase hepatic lipin-1 expression, and insulin acts antagonistically. J Lipid Res 2008;49(5):1056-67.

39. Ismail TA, Soliman MM, Nassan MA, Mohamed DI. Antihypercholesterolemic effects of mushroom, chrysin, curcumin and omega-3 in experimental hypercholesterolemic rats. J Food Nutr Res 2015;3(2):77-87.

40. McQuaid SE, Hodson L, Neville MJ, Dennis AL, Cheeseman J, Humphreys SM, et al. Downregulation of adipose tissue fatty acid trafficking in obesity: A driver for ectopic fat deposition? Diabetes 2011;60(1):47-55.

41. Aziz N, Mehmood MH, Gilani AH. Studies on two polyherbal formulations (ZPTO and ZTO) for comparison of their antidyslipidemic, antihypertensive and endothelial modulating activities. BMC 
Complement Altern Med 2013;13:371.

42. Sahu M, Anamthathmakula P, Sahu A. Phosphodiesterase-3B-cAMP pathway of leptin signalling in the hypothalamus is impaired during the development of diet-induced obesity in FVB/N mice. J Neuroendocrinol 2015;27(4):293-302.

43. Ohyama K, Nogusa Y, Suzuki K, Shinoda K, Kajimura S, Bannai M. A combination of exercise and capsinoid supplementation additively suppresses diet-induced obesity by increasing energy expenditure in mice. Am J Physiol Endocrinol Metab 2015;308(4):E315-23.

44. Li B, Lang N, Cheng ZF. Serum levels of brain-derived neurotrophic factor are associated with diabetes risk, complications, and obesity: A cohort study from Chinese patients with type 2 diabetes. Mol Neurobiol 2016;53(8):5492-9.

45. Gotthardt JD, Verpeut JL, Yeomans BL, Yang JA, Yasrebi A, Roepke TA, et al. Intermittent fasting promotes fat loss with lean mass retention, increased hypothalamic norepinephrine content, and increased neuropeptide $\mathrm{Y}$ gene expression in diet-induced obese male mice. Endocrinology 2016;157(2):679-91.

46. Jabbour G, Lemoine-Morel S, Casazza GA, Hala Y, Moussa E, Zouhal H. Catecholamine response to exercise in obese, overweight, and lean adolescent boys. Med Sci Sports Exerc 2011;43(3):408-15.

47. Meireles M, Rodríguez-Alcalá LM, Marques C, Norberto S, Freitas J, Fernandes I, et al. Effect of chronic consumption of blackberry extract on high-fat induced obesity in rats and its correlation with metabolic and brain outcomes. Food Funct 2016;7(1):127-39.

48. Carlin J, Hill-Smith TE, Lucki I, Reyes TM. Reversal of dopamine system dysfunction in response to high-fat diet. Obesity (Silver Spring) 2013;21(12):2513-21

49. Jean A, Conductier G, Manrique C, Bouras C, Berta P, Hen R, et al. Anorexia induced by activation of serotonin 5 -HT4 receptors is mediated by increases in CART in the nucleus accumbens. Proc Natl Acad Sci U S A 2007;104(41):16335-40.

50. Kim JH, Choi JH. Pathophysiology and clinical characteristics of hypothalamic obesity in children and adolescents. Ann Pediatr Endocrinol Metab 2013;18(4):161-7.
51. Egawa T, Hamada T, Ma X, Karaike K, Kameda N, Masuda S, et al. Caffeine activates preferentially a1-isoform of 5'AMP-activated protein kinase in rat skeletal muscle. Acta Physiol (Oxf) 2011;201(2):227-38.

52. Bhaktha G, Shantaram M, Nayak S. Beneficial effects of coffee and maintenance of uric acid levels. Int J Pharm Pharm Sci 2016;8(4) (4):393-5.

53. Chioma OO, Victor NO, Emeka GA. Effect of piper nigrum Leaves extract on lipid profile status on alloxan induced diabetic rats. World Appl Sci J 2014;32(1):34-9.

54. Huang CC, Tung YT, Huang WC, Chen YM, Hsu YJ, Hsu MC Beneficial effects of cocoa, coffee, green tea, and garcinia complex supplement on diet induced obesity in rats. BMC Complement Altern Med 2016;16:100.

55. Vitaglione P, Morisco F, Mazzone G, Amoruso DC, Ribecco MT, Romano A, et al. Coffee reduces liver damage in a rat model of steatohepatitis: The underlying mechanisms and the role of polyphenols and melanoidins. Hepatology 2010;52(5):1652-61.

56. Wu T, Willett WC, Hankinson SE, Giovannucci E. Caffeinated coffee, decaffeinated coffee, and caffeine in relation to plasma C-peptide levels, a marker of insulin secretion, in U.S. women. Diabetes Care 2005;28(6):1390-6.

57. Sharma G, Mishra B. Piperine - A therapeutic agent and bioavalibility enhancer. J Pharm Res 2007;6:129-33.

58. Heilbronn LK, Clifton PM. C-reactive protein and coronary artery disease: Influence of obesity, caloric restriction and weight loss. J Nut Biochem 2002;13(6):316-21.

59. Reyes-Izquierdo T, Argumedo R, Shu C, Nemzer B, Pietrzkowski ZB Stimulatory effect of whole coffee fruit concentrate powder on plasma levels of total and exosomal brain-derived neurotrophic factor in healthy subjects: An acute within-subject clinical study. Food Nutr Sci 2013;4:984-90.

60. Li G, Ruan L, Chen R, Wang R, Xie X, Zhang M, et al. Synergistic antidepressant-like effect of ferulic acid in combination with piperine: Involvement of monoaminergic system 2015;30(6):1505-14. 